\title{
NOVEL SYNTHESIS AND CHARACTERISATION OF SOME BENZYLIDENE DERIVATIVES OF GLYCOSYL THIOCARBAMIDES
}

\author{
Samidha S. Kadu* and G. V. Korpe \\ P.G. Department of Chemistry, Shri.Shivaji College, Akola-444003 (MS) India. \\ *E-mail: samidhakadu@gmail.com
}

\begin{abstract}
Several per- $O$-acetyl and per- $O$-benzoyl glycosylthiocarbamides were synthesized by the interaction of glycosylisothiocyanates and $o$-phenylenediamine. While these thiocarbamideson further reactions with anisaldehyde give respective benzylidene derivatives. The identities of these newly synthesized compounds were established on the basis of usual chemical transformations, IR, ${ }^{1} \mathrm{H}$ NMR, ${ }^{13} \mathrm{C}$ NMR and Mass spectral studies. All the synthesized compounds have been evaluated for their antibacterial and antifungal activity against different bacteria and fungi by the agar diffusion method.
\end{abstract}

Keywords: Glycosyl thiocarbamides, Anisaldehyde, Benzylidene glycosylthiocarbamides, antimicrobial analysis.

(c) RASĀYAN. All rights reserved

\section{INTRODUCTION}

Thiourea, having a considerably wide range of applications, is a functional organic compound similar to urea, except that the oxygen atom is replaced by a sulfur atom. The properties of urea and thiourea differ significantly because of the difference in electronegativity between sulfur and oxygen. Thus, thiourea is a versatile reagent in organic synthesis. Derivatives of urea, thiourea and thiosemicarbazide play a vital role in the field of medicinal chemistry by regulating various pharmacological activities. Literature survey reveals that urea and thiourea derivatives showed a broad spectrum of biological Activities as anti-HIV, antiviral, HDL- elevating antibacterial, analgesic properties ${ }^{1}$. It is produced and consumed by the thousands of tons throughout the world every year. ${ }^{2}$ The main application of thiourea is in textile processing. ${ }^{3}$

The reaction of amines and aromatic aldehydes to generate imines is a well-knownand extensively studied method to generate these compounds. More than one hundred and fifty years the Schiff bases are an important class of organic compounds in chemical, medical and pharmaceutical areas. Schiff bases have shown a wide range of biological activities, such as antipyretic ${ }^{4}$, antimalarial ${ }^{5}$, antiproliferative ${ }^{6}$, antiviral $^{7}$, antitumor ${ }^{8}$, antioxidant ${ }^{9}$, antibacterial ${ }^{10}$, and antifungal ${ }^{11}$. Recently, the hydroxy-substituted Schiff bases have received considerable attention due to good anticancer activity; for example, Luiet al. report a new Schiff base ( $N$-(3,4-dihydroxybenzylidene) ferroceneamine, with an excellent biological activity against the HeLa cancer cell line, where the $o$-dihydroxy groups play an important role. ${ }^{12,13}$

Schiff bases have received a considerable amount of attention from many researchers owing to their importance in exhibiting thermochromism and photochromism ${ }^{14-17}$. Thiourea compounds work as building blocks in the synthesis of heterocyclic compounds. Substituted thioureas have recently gained much interest in the preparation of a wide variety of biologically active compounds ${ }^{18,19}$.

Thioureas are important organic compounds which possess high biological activity, act as corrosion inhibitors and antioxidant, and are polymer components ${ }^{20}$. Heterocyclic thiourea has been reported as a new class of potent non-nucleoside inhibitors of human viruses type 1 reveresAriansscriptas (NNRTIS). 21,22

In view of the advantage conferred by glycosylthiourea and Schiff bases, it was interesting to carry out the synthesis of various per- $O$-acetyl and per- $O$-benzoyl glycosyl-thiocarbamides and their benzylidene

Rasayan J. Chem., 12(3), 1058-1062(2019)

http://dx.doi.org/10.31788/RJC.2019.1235128

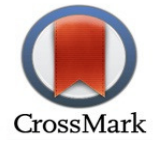


RASĀYAN J. Chem.

Vol. 12 | No. 3 |1058 - 1062| July - September | 2019

derivatives by the interaction of per- $O$-acetyl and per- $O$-benzoylglycosylisothiocyanate withophenylenediamine and further with anisaldehyde. (Scheme-1 and Scheme-2).

\section{EXPERIMENTAL}

All melting points were uncorrected and obtained in a capillary using a paraffin bath. Specific rotations of the newly synthesized compounds were measured on Equip-Tronic digital polarimeter model No. EQ 801 at $30^{\circ} \mathrm{C}$ in $\mathrm{CHCl}_{3}$. IR spectra were recorded on Shimadzu FTIR spectrophotometer, ${ }^{1} \mathrm{H}$ NMR has obtained on a BrukerDRX-300 (300 MHz FT NMR) NMR spectrophotometer in $\mathrm{CDCl}_{3}$ solution with TMS as an internal reference. ${ }^{13} \mathrm{C}$ NMRwas obtained on a Bruker DRX-300 (300 MHz FT NMR) NMR spectrophotometer in $\mathrm{CDCl}_{3}$ solution. The Mass spectra were recorded on a Jeol SX-102 FAB mass spectrometer. The purity of the compound was checked by thin layer chromatography using Merck silica gel coated aluminium plates and petroleum ether : ethyl acetate as eluent and iodine vapors as a visualizing agent.
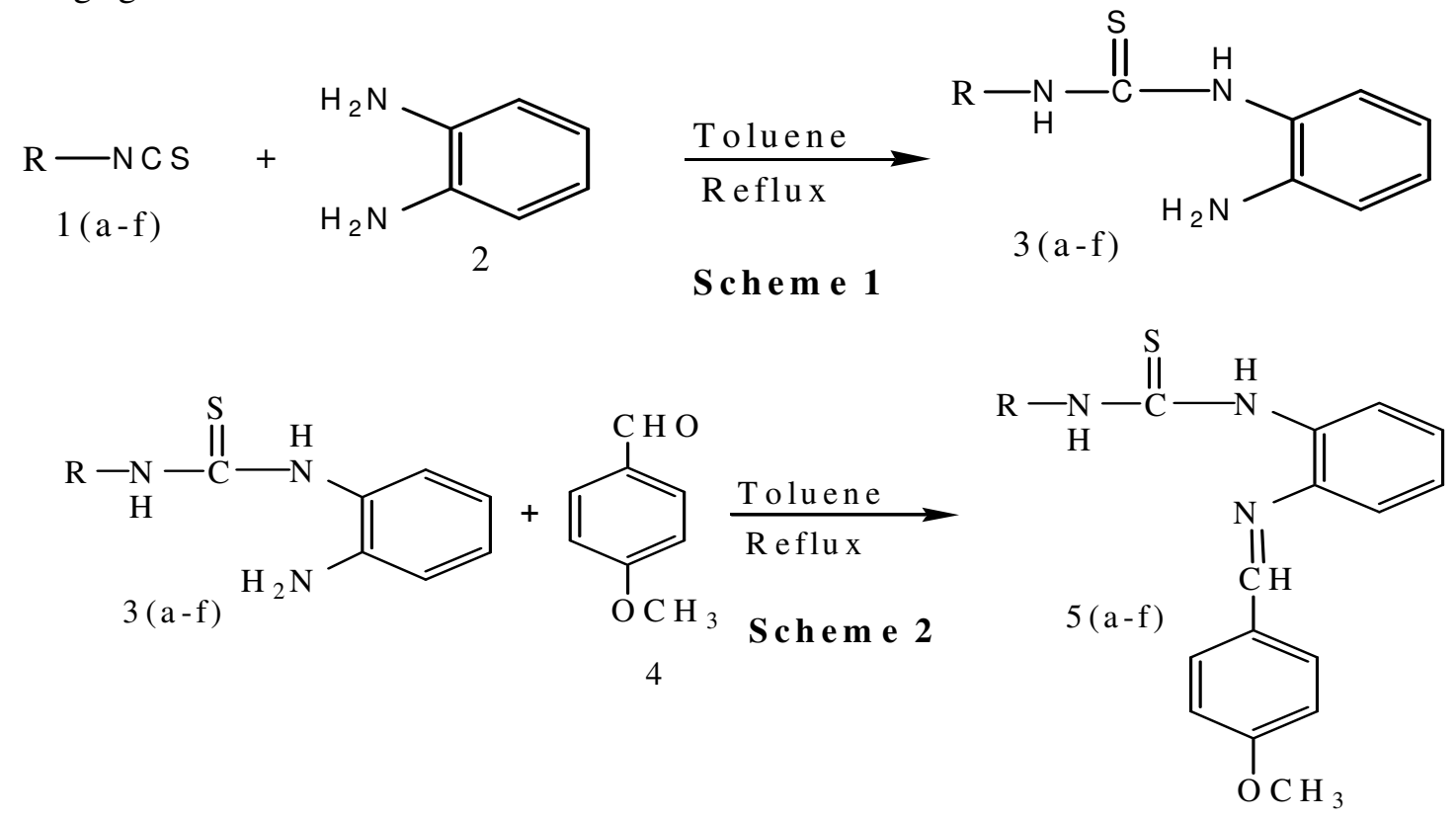

Where, $\mathrm{R}=$ (a) Tetra- $O$-acetyl- $\beta$-D-glucopyranosyl, (b) Hepta- $O$-acetyl- $\beta$-D-lactosyl, (c) Hepta- $O$-acetyl- $\beta$-Dmaltosyl, (d)Tetra- $O$-benzoyl- $\beta$-D-glucopyranosyl, (e) Hepta- $O$-benzoyl- $\beta$-D-lactosyl, (f) Hepta- $O$-benzoyl- $\beta$-Dmaltosyl

\section{Synthesis of per-O-acetyl and per-O-benzoyl glycosylisothiocyanates}

The required glycosyl isothiocyanates ${ }^{22}$ were prepared by the earlier known method by the interaction of glycosyl bromide and lead thiocyanate, while $o$-phenylenediamine and anisaldehyde were purchased from S. D. fine-chem. limited company(SDFCL). All the chemicals used were of high purity.

1-Phenyl-3-[2'- (4-methoxy) benzylidene amino] -tetra-O-acetyl- $\beta$-D-glucosylthiocarbamide (5a) 1-phenyl-3-[2'-(4-methoxy) benzylidene amino]-tetra- $O$-acetyl- $\beta$ - D - glucosylthiocarbamide (5a) was synthesized by interaction of 1-phenyl-3-(2'-amino)-tetra- $O$-acetyl- $\beta$-Dglucosylthiocarbamide (3a) $(0.001 \mathrm{M}, 0.785 \mathrm{~g})$ and anisaldehyde $(0.001 \mathrm{M}, 0.133 \mathrm{~g})$ (5) in toluene, was refluxed for $2 \mathrm{~h}$ while monitoring the reaction by TLC. Toluene was distilled off and resultant syrupy mass was triturated several times with petroleum ether $\left(60-80{ }^{\circ} \mathrm{C}\right)$, to afford granular solid (5a) crystallized from the chloroform-petroleum ether (Scheme-3). The characterization of product (5a) was established by usual chemical transformations, $\mathrm{IR}^{22},{ }^{1} \mathrm{H} \mathrm{NMR}^{23-29},{ }^{13} \mathrm{C} \mathrm{NMR}$ and Mass ${ }^{30}$ spectral studies.

\section{RESULTS AND DISCUSSION}

We have developed a simple and highly reliable route for the synthesis of $N$-Glycosylthiocarbamides and its corresponding benzylidene derivatives. This strategy can be successfully applied to prepare a wide 
range of $\mathrm{N}$-Glycosylbenzylidene derivatives which can be widely used for the preparation of biologically active molecules and good active lead in Medicinal Chemistry.

Thus the synthesized novel $\mathrm{N}$-Glycosylthiocarbamides and its corresponding benzylidene derivatives exhibit antibacterial and antifungal activities against the organism tested. The method adopted in the synthesis and investigation is simple, efficient and inexpensive in synthesizing pharmacologically important molecule.

\section{1-Phenyl-3-[2'- (4-methoxy) benzylidene amino]-tetra-O-acetyl- $\beta$-D-glucopyranosylthiocarbamide} (5a)

Yield : 1.84g; Analysis for $\mathrm{C}_{29} \mathrm{H}_{33} \mathrm{O}_{10} \mathrm{~N}_{3} \mathrm{~S} ; \mathrm{C}, 56.59 ; \mathrm{H}, 5.37 ; \mathrm{N}, 6.83 ; \mathrm{S}, 5.20$ Found C, 56.68; H, 5.35; N, 6.80; S, 5.26; IR (KBr) $v \mathrm{~cm}^{-1}: 3332$ (N-H str.), 3061 (Ar C-H str.), 2949 (Ali C-H str.), 1735 (C=O str.), 1512, 1452 (Ar C=C str.), 1396 (C=S str.), 1284 (C-O str.), 1178 (C-N str.); ${ }^{13} \mathrm{C} \mathrm{NMR}\left(\mathrm{CDCl}_{3}\right) \delta$ ppm : 166-160, 133-123, 116, 77, 73, 71, 69, 63, 55.

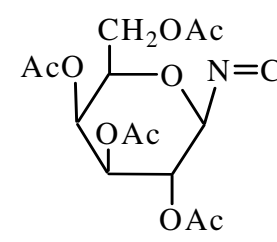

$1 \mathrm{a}$
2

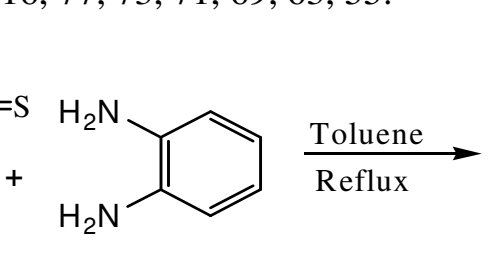

$3 \mathbf{a}$

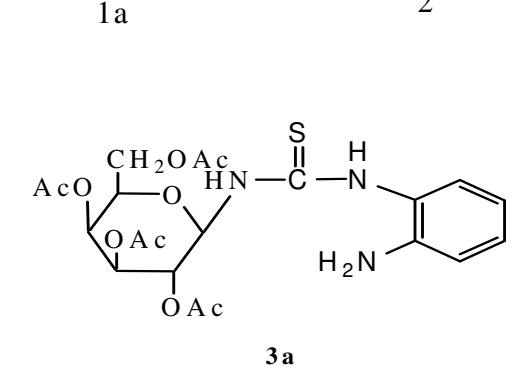

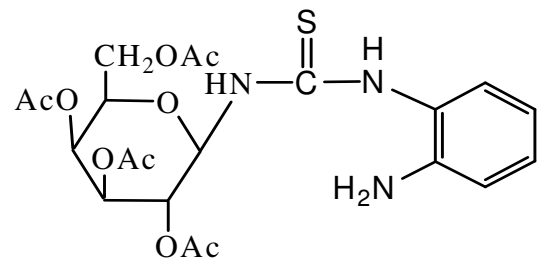

$3 \mathrm{a}$

4 
RASĀYAN J. Chem.

Vol. 12 | No. 3 |1058 - 1062| July - September | 2019

6.1-4.3 (7H, glucosyl-H), $1.9(1 \mathrm{H}, \mathrm{N}-\mathrm{H}), 6.7(1 \mathrm{H}, \mathrm{N}-\mathrm{H}), 6.9(1 \mathrm{H},=\mathrm{CH}), 3.8\left(3 \mathrm{H}, \mathrm{OCH}_{3}\right), 8-6.9(28 \mathrm{H}, \mathrm{Ar}-$ H) Mass Analysis : Molecular ion peak $\left(\mathrm{M}^{+}\right)$863, $\mathrm{M}^{+}+2865$ related observed peaks 746, 712, 579, 502, $225,105$.

1-Phenyl-3-[2'-(4-methoxy) benzylidene amino]-hepta-O-benzoyl- $\beta$-D-lactosylthiocarbamide (5e) Yield : $2.12 \mathrm{~g}$; Analysis for $\mathrm{C}_{76} \mathrm{H}_{63} \mathrm{O}_{18} \mathrm{~N}_{3} \mathrm{~S} ; \mathrm{C}, 68.21 ; \mathrm{H}, 4.71 ; \mathrm{N}, 3.14 ; \mathrm{S}, 2.39$ Found $\mathrm{C}, 68.23 ; \mathrm{H}, 4.76$; $\mathrm{N}, 3.12 ; \mathrm{S}, 2.41{ }^{1} \mathrm{H}$ NMR $\left(\mathrm{CDCl}_{3}\right) \delta \mathrm{ppm}: 5.7-4.0(14 \mathrm{H}$, lactosyl-H), $3.6(1 \mathrm{H}, \mathrm{N}-\mathrm{H}), 5.8(1 \mathrm{H}, \mathrm{N}-\mathrm{H}), 5.9$ $(1 \mathrm{H},=\mathrm{CH}), 3.9\left(3 \mathrm{H}, \mathrm{OCH}_{3}\right), 8.1-6.6(43 \mathrm{H}, \mathrm{Ar}-\mathrm{H})$; Mass Analysis : Molecular ion peak $\left(\mathrm{M}^{+}\right) 1337$, related observed peaks $1278,1185,916,579,225,195,121,105$

1-Phenyl-3-[2'-(4-methoxy)benzylidene amino]-hepta-O-benzoyl- $\beta$-D-maltosylthiocarbamide (5f) Yield : 2.081g; Analysis for $\mathrm{C}_{76} \mathrm{H}_{63} \mathrm{O}_{18} \mathrm{~N}_{3} \mathrm{~S} ; \mathrm{C}, 68.21 ; \mathrm{H}, 4.71 ; \mathrm{N}, 3.14 ; \mathrm{S}, 2.39$ Found $\mathrm{C}, 68.25 ; \mathrm{H}, 4.70$; $\mathrm{N}, 3.10 ; \mathrm{S}, 2.40 ;{ }^{1} \mathrm{H}$ NMR $\left(\mathrm{CDCl}_{3}\right) \delta \mathrm{ppm}: 6.2-3.7(14 \mathrm{H}$, maltosyl-H), $0.8(1 \mathrm{H}, \mathrm{N}-\mathrm{H}), 7.1(1 \mathrm{H}, \mathrm{N}-\mathrm{H}), 7.2$ $(1 \mathrm{H},=\mathrm{CH}), 1.8\left(3 \mathrm{H}, \mathrm{OCH}_{3}\right), 8.1-7.2(43 \mathrm{H}, \mathrm{Ar}-\mathrm{H})$; Mass Analysis : Molecular ion peak $\left(\mathrm{M}^{+}\right)$1337, related observed peaks $1278,1216,930,579,345,225,182,105$

\section{Antimicrobial Activity}

These newly synthesized thiocarbamides were screened for their microbial activity against different pathogenic microbes for their antibacterial and antifungal activities using well method ${ }^{31}$. The compounds were screened for antibacterial activity against E. coli, S. aureus, $P$. vulgaris and for antifungal activity against $C$. albicancs and $A$. niger in potato dextrose agar medium.

\section{ACKNOWLEDGMENT}

Authors are thankful to SAIF, CDRI, Lucknow and SAIF Chandigarh for providing spectral data. Authors are also thanks to,Head Department of Chemistry and Dr. R. M. Bhise, Principal, Shri. Shivaji College of Arts, Commerce and Science, Akola for encouragement and providing necessary facilities. Authors are also thankful to The Dean, Govt. Medical College, Akola for providing necessary facilities in the Microbiology Department.

\section{REFERENCES}

1 S. S. Kadu and G. V. Korpe, Rasayan J. Chem., 9(1), 40(2016).

2 Cemil ALKAN, Yusuf TEK, Derya KAHRAMAN, Turk J Chem.,35, 769 (2011), DOI:10.3906/kim-1008-3

3 B. Mertschenk, F. Beck and W. Bauer, Ullmann's Encyclopedia of Industrial Chemistry, Wiley-VCH, Weinheim,(2002).

4 G. Valli, K.Ramu, P. Mareeswari and A. T.Thirupathi, J. Pharm. Res.,5, 3453 (2012).

5 S. E. Harptrite, S.D. Collins, A.Oksman, D. E. Goldberg and V.Sharma,Med. Chem.,4, 392 (2008).

6 K.Sztanke, A.Maziarka, A.Osinka and M.Sztanke, BioorgMed Chem., 21, 3648(2013).

7 K.S. Kumar, S.Ganguly, R.Veerasamy and E. De Clercg,Eur. J. Med. Chem.,45, 5474(2010).

8 S.Ren, R. Wang, K. Komatsu, P.Bonaz-Krause, Y.Zyrianov, C.E. McKenna, C.Csipke, Z. A. Tokes and E. J.Lien,J. Med. Chem.,45, 410(2002).

9 M.S.Alam, J. H. Choi and D.U. Lee, Bioorg. Med. Chem., 20, 4103 (2012).

10 H.J. Zhang, X. Qin, K. Liu, D.D. Zhu, X. M. Wang and H. L.Zhu,Bioorg.Med. Chem.,19, 5708 (2011).

11 P.Przybylski, A.Huczynski, K.Pyta, B. Brzezinski and F.Bartl,Curr. Org. Chem.,13, 124(2009).

12 W. Chen, W.Ou, L. Wang, Y.Hao, J. Cheng, J. Li and Y. N.Liu,Dalton Trans,42, 15678(2013).

13 V. M. Jiménez-Pérez, B. M. Muñoz-Flores, L.M.Blanco Jerez, A. Gómez, L. D. Rangel, R. ChanNavarro, N.Waksma and, R.Ramírez-Durón, Int. J. Electrochem. Sci., 9,7431(2014).

14 E. Hadjoudis,M.Vittorakis, and I.Moustakali-Mavridis,Tetrahedron,43, 1345(1987).

15 E. Hadjoudis,A.Rontoyianni,K.Ambroziak, T. DziembowskaandI. Mavridis, J. Photochem. Photobiol. A Chem.,162, 521(2004).

16 A. Oshima, A.Momotake and T.Arai,J. Photochem. Photobiol. A Chem., 162, 473(2004).

17 G. Y. Yeap, Ha S T Ishizawa, K. Suda, P. L.Boey, and W. A. K.Mahmood,J. Mol. Struct., 658, 87 (2003) 
18 J.S.Ren, J.Diprose, J. Warren, R.M.Esnouf, L.E. Bird, S.Ikemizu, M. Slater, J. Milton, J.Balzarini, D. L. Stuart and D.K.Stammers, J Biol. Chem.,275, 5633(2000).

19 F.T.Elmali, U.Avciata and N.Demirhan,Main Group Chemistry,10, 17(2011).

20 A.R.Katritzky and M.F.Gordeev, J. Chem. Soc., 1, 2199(1991).

21 J Pen, J. Diprese, R. Esnonf, J. Milton,J.Balzarini and D. Stammers, J. Biol. Chem.,275, 5633(2000).

22 G. Heinisch, B.Matuzzczak, S.Pachier and D.Rakawitz, Antivir. Chem. Chemother,8, 443(1997).

23 S.P.Deshmukh and M. G. Paranjape,Oriental J. Chem.,16(1),143(2000).

24 Zhiqun Dai, Fanqui Qu, Wei Wu and Chegtai Lie, J. Chem. Res., (S) 3, 106(2001), DOI: $10.3184 / 030823401103169270$

25 R.Varma, S.Y.Kulkarni, J. J. Jose and V.S.Pansare, Carbohydr. Res., 133, 25(1984), DOI: 10.1016/0008-6215(84)85179-4

26 J.Isac-Garcia, et.al. Eur. J. Org. Chem., 2, 383(2001), DOI: 10.1002/10990690(200101)2001:2<383::AID-EJOC383>3.0.CO;2-N

27 J. L. Jimenez Blanco et.al., Synthesis,11,1911 (1999).

28 S. CaO, F. D. Tropper and R. Roy,Tetrahedron,51, 6679(1995), DOI: 10.1039/c4ob00128a

29 J. Lonngren and S. Svensson, “Adv. Carbohydr. Chem. Biochem.”, Academic, Press, New York, 39, 98 (1974).

30 H. Budzikiewiez, C.Djerassi and D. H. Williams, "Structural Elucidation of Natural Products by Mass Spectroscopy", 1964.

31 British Pharmacopaeia, "Biological Assay and test" The stationary Office Ltd., London, U.K.1998.

[RJC-5128/2018] 